\title{
Oral hairy leukoplakia: a clinical indicator of immunosuppression
}

\author{
Alexander Kreuter MD, Ulrike Wieland MD
}

Competing interests: Alexander Kreuter is a board member of Wyeth. Ulrike Wieland has received payment for lectures from Roche and bioMérieux.

This article has been peer reviewed.

\section{Affiliations: From the} Department of Dermatology, Venereology and Allergology (Kreuter), Ruhr University, Bochum, Germany; and the Institute of Virology (Wieland), University of Cologne, Cologne, Germany

Correspondence to: Dr. Alexander Kreuter, a.kreuter@derma.de

CMAJ 2011. DOI:10.1503 /cmaj.100841

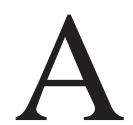
29-year-old man presented with nonpainful white lesions on his tongue that he had recently noticed while brushing his teeth. Testing for oral candidal infection by his general practitioner was negative. The patient was feeling otherwise healthy and had no further complaints. Clinical examination showed bilateral corrugated, adherent plaques located on the dorsal tongue surfaces (Figure 1). Testing for HIV was positive. The patient's CD4 count was 0.28 (normal $0.3-1.4$ ) $\times 10^{9} / \mathrm{L}$, and his viral load was 431000 HIV-1 RNA copies $/ \mathrm{mL}$. Ten weeks after the initiation of highly active antiretroviral therapy (HAART), all lesions had completely resolved.

Oral hairy leukoplakia, first described in 1984 , is a mucosal disease associated with Epstein-Barr virus infection and almost exclusively occuring in people with immunosupression. It occurs in up to $50 \%$ of patients with untreated HIV, particularly those whose CD4 count is less than $0.3 \times 10^{9} / \mathrm{L} .{ }^{1}$ The condition has a clear prognostic value for the subsequent development of AIDS and is classified as a Centers for Disease Control and Prevention category-B clinical marker of HIV disease. ${ }^{2}$ Oral hairy leukoplakia has also been described in conjunction with hematologic malignancy and organ and bone marrow transplantation, and in patients receiving systemic steroids. Rarely, it has been reported in the absence of immunosuppression. ${ }^{3}$

The pathogenesis of oral hairy leukoplakia is complex and includes an interplay of persistent Epstein-Barr virus replication and virulence, systemic immunosuppression and suppression of the local host immunity. ${ }^{3}$ The differential diagnoses include oral candidiasis, lichen planus, tobaccoassociated leukoplakia, human papillomavirusinduced oral intraepithelial neoplasia, and oral squamous cell carcinoma. In most instances, oral hairy leukoplakia can be diagnosed clinically and does not require a confirmatory biopsy. It
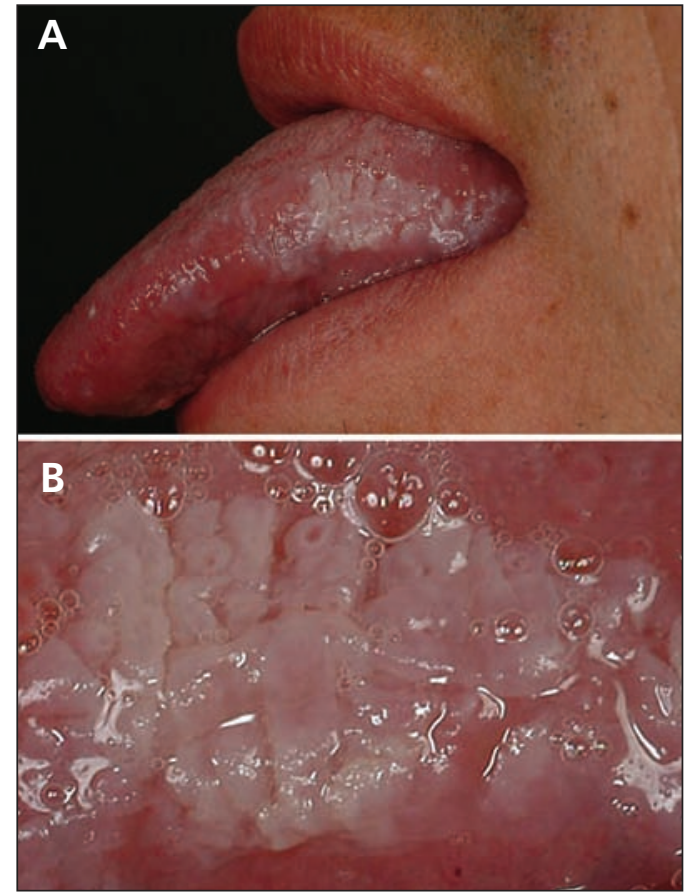

Figure 1: (A) Painless white adherent plaques on the dorsal tongue surfaces of a 29-year-old man. (B) Close-up view of a lesion: the surface of the patch has a corrugated appearance forming prominent folds.

does not require specific treatment and frequently resolves under HAART, if associated with HIV infection. ${ }^{4}$

\section{References}

1. Bravo IM, Correnti M, Escalona L, et al. Prevalence of oral lesions in HIV patients related to CD4 cell count and viral load in a Venezuelan population. Med Oral Patol Oral Cir Bucal 2006; 11:E33-9.

2. Centers for Disease Control and Prevention. 1993 revised classification system for HIV infection and expanded surveillance case definition for AIDS among adolescents and adults. MMWR 1992;41:RR-17.

3. Piperi E, Omlie J, Koutlas IG, et al. Oral hairy leukoplakia in HIV-negative patients: report of 10 cases. Int J Surg Pathol 2010; 18:177-83.

4. Nokta M. Oral manifestations associated with HIV infection. Curr HIV/AIDS Rep 2008;5:5-12. 